\section{Do Anthocyanins Function as Photoprotective Light Screens in Senescing Sugar Maple Leaves? Abby $\mathrm{K}$ van den Berg* and Timothy $\mathrm{D}$ Perkins}

Proctor Maple Research Center, University of Vermont, Underhill, Vermont, USA

\begin{abstract}
The hypothesis that anthocyanin pigments provide photoprotection in senescing leaves through visible light absorption was tested. Senescent red and non-senescent green sugar maple (Acer saccharum) leaves were subjected to a photoinhibitory high-irradiance, low-temperature treatment, and the response and recovery of chlorophyll a fluorescence parameters were measured. The light treatment was applied to either the adaxial or abaxial leaf surface in order to assess the physiological responses both with and without the potential light attenuation by anthocyanins located in the palisade mesophyll. Although abaxially-illuminated red leaves were significantly more negatively affected by the photoinhibitory treatment than adaxially-illuminated red leaves, both leaf types achieved the same level of recovery to pretreatment photochemical efficiency. In addition, for all parameters measured, the difference between adaxiallyand abaxially-illuminated leaves was not greater in red than in green leaves. This indicates that visible light absorption by anthocyanins in the palisade mesophyll did not provide significant photoprotection above the basic screening of light passing through the cells of the palisade mesophyll. These results suggest that visible light absorption by anthocyanins may not be a significant additional source of photoprotection in senescing sugar maple leaves, but may contribute to achieving a similar level of photoprotection provided by other mechanisms in nonanthocyanic senescing leaves.
\end{abstract}

Keywords: Anthocyanin; Autumn senescence; Maple; Photoinhibition; Photoprotection

*Corresponding author: Abby $\mathrm{K}$ van den Berg, Proctor Maple Research Center, University of Vermont, 58 Harvey Rd, Underhill, USA, Tel: +802-899-9926; E-mail: Abby.vandenBerg@uvm.edu

Citation: van den Berg AK, Perkins TD (2017) Do Anthocyanins Function as Photoprotective Light Screens in Senescing Sugar Maple Leaves? J Plant Sci Curr Res 1: 002

Received: November 06, 2017; Accepted: December 04, 2017; Published: December 18, 2017

Copyright: (c) 2017 van den Berg AK and Perkins TD. This is an open-access article distributed under the terms of the Creative Commons Attribution License, which permits unrestricted use, distribution, and reproduction in any medium, provided the original author and source are credited.

\section{Introduction}

Anthocyanins are water-soluble flavonoid pigments located primarily in the plant vacuole [1]. Their biosynthesis appears to be promoted by a number of factors, but they are often observed to accumulate in response to physiological stressors [2], including nutrient deficiency [3,4], UV-B radiation [5,6], ozone exposure [7], and low temperatures coupled with high irradiance light [8].

In general, anthocyanins are hypothesized to play a role in photoprotection of plant tissues. Anthocyanins absorb both visible and UV light [9], they are effective scavengers of oxygen radicals in vitro $[10,11]$, and evidence of their antioxidative function in vivo has been documented [12]. It is thought that by attenuating visible light as well as directly scavenging reactive oxygen species, anthocyanins may reduce photoinhibition [13-15] a decrease in photosynthetic efficiency resulting from the photoinactivation of photosystem II (PSII) and subsequent membrane damage by oxygen radicals generated when the supply of energy reaching the leaf exceeds its energy quenching capacity [16].

Several studies have linked anthocyanins with an increased ability to cope with photoinhibitory conditions [5,17-23]. However, others have failed to find a significant photoprotective benefit from anthocyanins [24-29], and some evidence of increased susceptibility to photoinhibition in anthocyanic leaf areas has been demonstrated [30].

The function of anthocyanins that occur specifically in senescing leaves has not been widely studied. In temperate regions, autumnal anthocyanin expression occurs when periods of high irradiance occur simultaneously with low temperatures, conditions which increase the likelihood that energy inputs will exceed a leaf's energy utilization capacity [16]. As many of the primary mechanisms of photoprotection require enzyme function $[16,31]$, it is possible that the efficacy of these mechanisms is reduced during these periods of low temperatures. In addition, during senescence pigment-protein complexes are dismantled to facilitate nutrient recycling, potentially reducing the ability of the leaf to capture energy while simultaneously increasing the likelihood of free radical generation [32]. It is thus possible that anthocyanins provide a timely mechanism of photoprotection that is neither enzymatic (potentially problematic due to reduced enzyme function at the colder temperatures which occur during leaf senescence in temperate regions) nor dependent upon a high degree of physiological or structural organization.

Further, as one of the dominant processes within senescing leaves is nutrient resorption, it has been hypothesized that the net ecological benefit of anthocyanin biosynthesis and photoprotection during senescence is in maintaining photosynthetic rates adequate to power resorption during a time when the likelihood of photoinhibition of photosynthesis is great [33], and several studies have presented evidence to support this hypothesis $[17,20,34]$. In contrast, however, at least one study observed marginal, if any, photoprotective effects of anthocyanins in senescing leaves [35].

Direct experimental evidence is needed to elucidate the potential photoprotective function of anthocyanins in senescing leaves. 
The location of anthocyanins in the palisade mesophyll layer of senescing sugar maple (Acer saccharum Marsh) leaves [36] is optimal for visible light attenuation [37], potentially reducing light penetration and protecting chloroplasts in the spongy mesophyll from excess energy inputs and subsequent photoinhibition.

The objective of this study was to test the hypothesis that visible light attenuation by anthocyanins provides photoprotection in senescing sugar maple leaves subjected to a high-irradiance and low-temperature treatment. The effect of the photoinhibitory treatment on photochemical yield and the recovery of photochemical efficiency to pretreatment levels were quantified by chlorophyll a fluorescence. The components of non photochemical quenching and further quantification of the extent of photoinhibition were determined through relaxation analysis.

\section{Materials and Methods}

\section{Leaf material}

Experiments were conducted on multiple dates from August through October 2003. For each experiment, individual, sun-exposed branches of sugar maple trees from a variety of sites in Chittenden County, Vermont were randomly selected for analysis. Experiments were conducted first with 21 green, non-senescent leaves (G) and later with 45 red, senescent leaves (R). Only red leaves with visibly evident chlorophyll in the abaxial surface were chosen. One healthy leaf from each branch was selected for analysis. Areas of the leaf that were appropriate for measurement (apparently healthy and free of visible damage) were delineated with a permanent marking pen to facilitate locating the test area during initial dark measurements. The branch was then re-cut underwater and stored at room temperature in the dark overnight (from 8 to $12 \mathrm{~h}$ ).

At the conclusion of the experiment, 2 leaf disks that were $6.45 \mathrm{~mm}$ diameter each were collected from each leaf for separate chlorophyll and anthocyanin extractions. The disks were chopped into fine pieces with a razor blade before being immersed in $2 \mathrm{~mL}$ of the appropriate extracting solution. Chlorophyll was extracted with an $80 \%$ acetone/ deionized water solution. Anthocyanins were extracted with acidified $80 \%$ methanol [37]. All extractions were completed in the dark at $4^{\circ} \mathrm{C}$. Spectrophotometric analyses of the pigments were performed using a Spectronic Genesys 8 spectrophotometer (Thermo Electron Corp., Waltham, Mass., USA) with a $10 \mathrm{~mm}$ light path. Total chlorophyll $(\mathrm{Chl})$ (chlorophyll $\mathrm{a}+\mathrm{b}$ ) was determined following methods and equations of Lichtenthaler and Wellburn [38] and was expressed on a leaf area basis. Anthocyanin content (Anth) was estimated as $A_{530}-0.24 A_{653}$ following the methods of Murray and Hackett [39] and Gould et al., [37].

\section{Photoinhibitory treatments}

In order to assess the physiological responses of anthocyanic senescing leaves both with and without the potential light attenuation by anthocyanins located in the palisade mesophyll, high irradiance light was applied from either the adaxial or abaxial leaf surface. For both treatment types, chlorophyll a fluorescence response was monitored in the abaxially-located chloroplasts. If anthocyanin accumulation in the palisade mesophyll helps protect the photo systems of underlying cells, then the influence of adaxial illumination (where light must travel through the anthocyanin layer) versus abaxial illumination (where the light bypasses the anthocyanin layer) should differ between red (containing anthocyanins) and green (with little anthocyanin content) leaves. All treatments were applied in a walk-in cold room with the ambient temperature around $0^{\circ} \mathrm{C}( \pm 2.0)$. Using a halogen fiber optic light source, each leaf was illuminated with $1500( \pm 50) \mu \mathrm{mol} \cdot \mathrm{m}^{-2} \cdot \mathrm{s}^{-1}$ photosynthetic photon flux density (PPFD) for $80 \mathrm{~min}$. Further cooling was achieved with a fan, and actual leaf temperatures averaged $2.8^{\circ} \mathrm{C}( \pm 0.6)$. Light treatments were applied to either the adaxial (D) or the abaxial (B) leaf surface to provide four treatment groups: adaxially-illuminated red (RD), abaxially-illuminated red (RB), adaxially-illuminated green (GD), and abaxially-illuminated green (GB) leaves.

\section{Chlorophyll $\boldsymbol{a}$ fluorescence measurements}

Chlorophyll $a$ fluorescence measurements were made using an OS1-FL modulated fluorometer (Opti-Sciences, Tyngsboro, MA) with a modulation intensity setting of 5 and saturation pulse length $0.8 \mathrm{~s}$. Prior to light treatment, working under a green safelight, a saturating light pulse was applied to measure dark-adapted minimal $\left(F_{o}\right)$ and maximal $\left(F_{m}\right)$ fluorescence. These values were used to calculate $F_{v} / F_{m}$, the dark-adapted maximum efficiency of PSII $\left[\left(F_{m}-F_{d}\right) / F_{m}\right]$ [40]. Chlorophyll fluorescence measurements were made at the end of the $80 \mathrm{~min}$ high irradiance light treatment. An initial saturating light pulse was applied to measure the maximum $\left(F_{m}{ }^{\prime}\right)$ and steady state $(F)$ fluorescence values in the light-adapted state. These values were used to calculate $\Phi_{\mathrm{PSII}}\left[\left(F_{m}{ }^{\prime}-F\right) / F_{m}{ }^{\prime}\right]$, the actual quantum yield of PSII in the light-adapted state. Immediately after this measurement, the actinic light was turned off and the treatment surface of the leaf was irradiated with far red light for $3 \mathrm{~s}$, following which an additional saturating light pulse was applied in order to measure $F_{o}$,' the minimal fluorescence value in the light-adapted state. These data were used to calculate the value of $F_{v}{ }^{\prime} / F_{m}{ }^{\prime}\left[\left(F_{m}{ }^{\prime}-F_{o}{ }^{\prime}\right) / F_{m}{ }^{\prime}\right]$, the quantum efficiency of PSII in the light-adapted state.

At the conclusion of light treatment, leaves were removed from the cold room and allowed to recover at room temperature $\left(15-20^{\circ} \mathrm{C}\right)$ under low light $\left(12 \pm 2 \mu \mathrm{mol} \cdot \mathrm{m}^{-2} \cdot \mathrm{s}^{-1} \mathrm{PPFD}\right)$. Fluorescence measurements made during recovery followed the same procedures as those made during the actinic light treatment and were taken at $5 \mathrm{~min}$ intervals for the first $90 \mathrm{~min}$ of recovery, 10min intervals for the next $90 \mathrm{~min}$, and $15 \mathrm{~min}$ intervals thereafter. Each leaf was monitored for a minimum $3 \mathrm{hr}$ post-treatment.

Relaxation analysis was conducted as outlined by Maxwell and Johnson [41]. For each leaf, the $\log$ of each $F_{m}$ ' value recorded from the end of the actinic light treatment through the recovery period was plotted over time. The y-intercept of the linear regression line of each plot was used to calculate values of fast- and slow-relaxing non photochemical quenching $\left(\mathrm{NPQ}_{\mathrm{f}}\right.$ and $\left.\mathrm{NPQ}_{\mathrm{s}}\right)$.

\section{Data Analysis}

For each treatment group the following parameters were calculated: mean anthocyanin content, mean chlorophyll content, mean dark-adapted $F_{v} / F_{m}$, mean $\Phi_{\text {PSII }}$ (as a percentage of pretreatment $F_{v}$ $F_{m}$ ) at the end of the $80 \mathrm{~min}$ treatment, mean maximum $F_{v}{ }^{\prime} / F_{m}{ }^{\prime}$ (as a percentage of pretreatment $F_{v} / F_{m}$ ) observed during the recovery period, mean $\mathrm{NPQ}_{\mathrm{f}}$, and mean $\mathrm{NPQ}_{\mathrm{s}}$. The light-adapted measure of photochemical efficiency, $F_{v}{ }^{\prime} / F_{m}$, was used to quantify the extent of recovery as leaves in this study recovered in minimal light (rather than complete darkness) in order to facilitate the repair of protein damage. All data were analyzed using SAS System software version 8e (SAS Institute, Cary, NC). Homogeneity of variance assumptions were verified using Levene's tests and normality assumptions were verified using Kolmogorov-Smirnov tests and normal probability plots. 
Anthocyanin and chlorophyll content were compared using Satterthwaite's t tests. For each fluorescence parameter, orthogonal contrasts were used to test the general hypotheses that (1) the means were equal within each color category and (2) the mean difference between RD and RB leaves was equal to the mean difference between GD and GB leaves. We hypothesized that if anthocyanins in senescing leaves were providing photoprotection to cells in the spongy mesophyll through visible light absorption, then the amount that responses of $\mathrm{RD}$ leaves exceeded those of RB leaves would be significantly greater than the differences between GD and GB leaves.

\section{Results and Discussion}

Red leaves had significantly less chlorophyll $(\mathrm{t}=-9.24, \mathrm{P}<0.001)$ and more anthocyanin $(\mathrm{t}=15.32, \mathrm{P}<0.001)$ than green leaves (Table 1). Pretreatment dark-adapted PSII efficiency, $F_{v} / F_{m}$, was also generally lower in red than in green leaves, indicating red leaves were experiencing a greater degree of long-term photoinhibition (Table 2 ). Because of these inherent differences in chlorophyll content and photochemical function as indicated by $F_{v} / F_{m}$, direct comparisons of fluorescence parameters between red and green leaves, particularly nonphotochemical quenching, would not have been appropriate. Pretreatment $F_{V} / F_{m}$ was not significantly different between abaxially- and adaxially-illuminated red or green leaves (Table 2).

\begin{tabular}{|c|c|c|c|}
\hline & n & Anth & Chl \\
\hline RD & 24 & $0.22 \pm 0.01$ & $0.08 \pm 0.01$ \\
\hline RB & 21 & $0.24 \pm 0.02$ & $0.08 \pm 0.01$ \\
\hline GD & 11 & $0.05 \pm 0.01$ & $0.19 \pm 0.01$ \\
\hline GB & 10 & $0.05 \pm 0.00$ & $0.17 \pm 0.01$ \\
\hline
\end{tabular}

Table 1: Anthocyanin and chlorophyll content of sugar maple leaves.

Note: Data show mean $( \pm \mathrm{SE})$ anthocyanin content (Anth) $\left(A_{530}-0.24\right.$ $\left.A_{653}\right)$, and total chlorophyll $(\mathrm{Chl})\left(\mu \mathrm{g} \cdot \mathrm{mm}^{-2}\right)$ for adaxially-illuminated red (RD) and green (GD) and abaxially-illuminated red (RB) and green (GB) sugar maple leaves exposed to an $80 \mathrm{~min}$ high-irradiance, low-temperature treatment.

The abaxial surfaces of sugar maple leaves are generally acclimated to a lower irradiance light environment than adaxial surfaces, and thus photoinhibition was expected to be greater in response to the abaxially applied light treatment in both red and green leaves. As expected, both RB and GB leaves were more negatively affected by the high irradiance light treatment relative to the adaxially-illuminated leaves of the same color. The proportion of light used for photochemistry $\left(\Phi_{\mathrm{PSII}}\right)$ at the end of the photoinhibitory treatment was lower (Table 2). Abaxially-illuminated leaves also exhibited a greater requirement for photoprotective processes and a greater degree of photoinhibition. Photoprotective processes indicated by $\mathrm{NPQ}_{\mathrm{f}}$, such as zeaxanthin formation as well as the state transition of light-harvesting chlorophyll proteins [41], were elevated in abaxially-illuminated leaves (Table 2). Slowly-relaxing NPQ was also elevated in these leaves, an indication that they were experiencing greater photoinhibition in response to the high irradiance light treatment, either as increased slowly-relaxing photoprotective processes, or increased damage to PSII reaction centers [41] (Table 2).

Although abaxially-illuminated leaves exhibited more negative effects from the light treatment, the recovery to pretreatment photochemical efficiency following removal from the photoinhibitory treatment was not significantly different between adaxially- and abaxially-illuminated red or green leaves (Table 2). Thus, regardless of which light treatment they received, red and green leaves were able to recover to approximately the same percentage of pretreatment photochemical efficiency.

Comparing the differences in the responses between $\mathrm{RD}$ and $\mathrm{RB}$ leaves to the differences between GD and GB leaves allows investigation of whether light absorption by anthocyanins in red-senescing leaves provides a photoprotective benefit to cells in the spongy mesophyll in addition to the existing protection afforded by light passing through the cells of the palisade mesophyll. Thus, we hypothesized that if anthocyanins were providing photoprotection through visible light screening, then the differences between responses of RD and RB leaves would be significantly greater than the differences between GD and GB leaves, indicating that light absorption by anthocyanins in the RD treatment leaves provided a significant enhancement to their ability to cope with and recover from the photoinhibitory treatment. However, for all parameters measured, the difference between adaxially- and abaxially-illuminated leaves was not greater in red than in green leaves (Table 2). This indicates that the ability to cope with the photoinhibitory treatment was not enhanced in red leaves which received the light treatment through the anthocyanin layer in the palisade mesophyll. Thus, light attenuation by anthocyanins did not enhance the maintenance of photochemical function during the light treatment nor did it reduce the requirement for photoprotective processes or the occurrence of photoinhibition in response to the treatment. It also did not appear to enhance the recovery of photochemical efficiency to pretreatment levels.

The red-senescing leaves in this study were less photosynthetically functional than the green, growing-season leaves; they had lower chlorophyll contents and greater degrees of long-term photoinhibition. Yet, despite reduced function, red-senescing leaves which received the light treatment through the anthocyanin layer exhibited a similar degree of photoinhibition relative to abaxially-illuminated red leaves compared to the relative responses of adaxially- and abaxially-illuminated green leaves. Thus, it may be that leaves receiving the light treatment through an anthocyanic palisade mesophyll may have experienced a photoprotective benefit of visible light absorption by anthocyanins, but only to a degree which afforded them a similar level of photoprotection as the more photosynthetically functional green leaves receiving the treatment through a non-anthocyanic palisade mesophyll. This is consistent with results observed by van den Berg et al., [42], which found that anthocyanins in the palisade mesophyll of sugar maple leaves did not significantly attenuate profiles of light absorption, but may have conferred a general source of photoprotection by absorbing green light and reducing the total amount of light available to be absorbed by chlorophyll. Thus, it may be that anthocyanins provide photoprotection in senescing sugar maple leaves to a similar degree as what is provided by other mechanisms (e.g. xanthophyll cycle, chloroplast movements, etc.) in nonanthocyanic senescing leaves, and thus that anthocyanins are simply one means of achieving the same photoprotective result as other mechanisms in nonanthocyanic leaves. This may indeed be an important contribution to protecting photosynthetic systems as leaf chlorophyll content decreases during the senescence period, and suggests that numerous photoprotective processes may act together to facilitate the maintenance of photosynthetic function during the senescence period and potentially confer a broader, more long-term benefit by facilitating nutrient resorption. 
Citation: van den Berg AK, Perkins TD (2017) Do Anthocyanins Function as Photoprotective Light Screens in Senescing Sugar Maple Leaves? J Plant Sci Curr Res 1: 002

\begin{tabular}{|c|c|c|c|c|c|c|}
\hline Parameter & Hypothesis Tested & RD & RB & GD & GB & $\mathbf{P}$ \\
\hline \multirow{4}{*}{$F_{v} / F_{m}$} & & $0.659(0.013)$ & $0.644(0.014)$ & $0.777(0.009)$ & $0.779(0.008)$ & \\
\hline & $\mathrm{RD}=\mathrm{RB}$ & & & & & 0.3516 \\
\hline & $\mathrm{GD}=\mathrm{GB}$ & & & & & 0.9331 \\
\hline & $(\mathrm{RD}-\mathrm{RB})=(\mathrm{GD}-\mathrm{GB})$ & & & & & 0.5511 \\
\hline \multirow{4}{*}{$\Phi_{\mathrm{PSII}}$} & & $22.8(2.99)$ & $14.3(2.28)$ & $26.1(3.77)$ & $16.6(3.56)$ & \\
\hline & $\mathrm{RD}=\mathrm{RB}$ & & & & & 0.0279 \\
\hline & $\mathrm{GD}=\mathrm{GB}$ & & & & & 0.0865 \\
\hline & $(\mathrm{RD}-\mathrm{RB})=(\mathrm{GD}-\mathrm{GB})$ & & & & & 0.892 \\
\hline \multirow{4}{*}{$\mathrm{NPQ}_{\mathrm{f}}$} & & $0.19(0.012)$ & $0.24(0.013)$ & $0.22(0.017)$ & $0.27(0.010)$ & \\
\hline & $\mathrm{RD}=\mathrm{RB}$ & & & & & 0.0008 \\
\hline & $\mathrm{GD}=\mathrm{GB}$ & & & & & 0.074 \\
\hline & $(\mathrm{RD}-\mathrm{RB})=(\mathrm{GD}-\mathrm{GB})$ & & & & & 0.622 \\
\hline \multirow{4}{*}{$\mathrm{NPQ}_{\mathrm{s}}$} & & $0.09(0.008)$ & $0.16(0.012)$ & $0.14(0.010)$ & $0.19(0.007)$ & \\
\hline & $\mathrm{RD}=\mathrm{RB}$ & & & & & 0.0001 \\
\hline & $\mathrm{GD}=\mathrm{GB}$ & & & & & 0.0067 \\
\hline & $(\mathrm{RD}-\mathrm{RB})=(\mathrm{GD}-\mathrm{GB})$ & & & & & 0.5286 \\
\hline \multirow{4}{*}{$F_{v}^{\prime} / F_{m}^{\prime}$} & & $87.8(1.47)$ & $88.9(1.07)$ & $95.6(1.05)$ & $91.9(1.72)$ & \\
\hline & $\mathrm{RD}=\mathrm{RB}$ & & & & & 0.5191 \\
\hline & $\mathrm{GD}=\mathrm{GB}$ & & & & & 0.146 \\
\hline & $(\mathrm{RD}-\mathrm{RB})=(\mathrm{GD}-\mathrm{GB})$ & & & & & 0.1189 \\
\hline
\end{tabular}

Table 2: Chlorophyll a fluorescence parameters obtained from sugar maple leaves exposed to an 80min high-irradiance, low-temperature treatment.

Note: Data represent means $( \pm \mathrm{SE}$ ) for adaxially-illuminated red $(\mathrm{RD})$ and green $(\mathrm{GD})$ and abaxially-illuminated red $(\mathrm{RB})$ and green $(\mathrm{GB})$ sugar maple leaves. Sample sizes for all analyses were $\mathrm{RD}=24, \mathrm{RB}=21, \mathrm{GD}=11$ and $\mathrm{GB}=10$, except tests of $\Phi_{\mathrm{PSII}}$, for which $\mathrm{RD}=23$ and $\mathrm{RB}=20 . \mathrm{P}-\mathrm{values}$ are for orthogonal contrasts testing the following hypotheses for each parameter: (1) the means within each color category were equal and (2) the mean difference between RD and RB leaves was equal to the mean difference between GD and GB leaves. $F_{v} / F_{m}=$ pretreatment dark-adapted PSII efficiency; $\Phi_{\mathrm{PSI}}=$ photochemical yield at the end of treatment (as a percentage of pretreatment $F_{v} / F_{m}$ ); $F_{v}{ }^{\prime} / F_{m}{ }^{\prime}=$ maximum photochemical efficiency observed during recovery from the treatment (as a percentage of pretreatment $\left.F_{v} / F_{m}\right) ; \mathrm{NPQ}_{\mathrm{f}}=$ fast-relaxing non photochemical quenching; and $\mathrm{NPQ}_{\mathrm{s}}$ = slow-relaxing nonphotochemical quenching.

\section{Acknowledgements}

This research was funded by a grant from the U.S. Environmental Protection Agency. We thank Dr. Paul Schaberg and Dr. Thomas Vogelmann for their helpful comments on this research.

\section{References}

1. Strack D (1997) Phenolic metabolism. In: Dey PM, Harborne JB (eds.). Plant Biochemistry. Academic Press, Massachusetts, USA.

2. Chalker-Scott L (1999) Environmental significance of anthocyanins in plant stress responses. Photochem Photobio 70: 1-9.

3. Bongue-Bartelsman M, Phillips DA (1995) Nitrogen stress regulates gene expression of enzymes in the flavonoid biosynthetic pathway of tomato. Plant Physiol and Biochem 33: 539-546.

4. Trull MC, Guiltinan MJ, Lynch JP, Deikman J (1997) The responses of wild-type and ABA mutant Arabidopsis thaliana plants to phosphorous starvation. Plant Cell Environ 20: 85-92.

5. Mendez M, Jones DG, Manetas Y (1999) Enhanced UV-B radiation under field conditions increases anthocyanin and reduces the risk of photoinhibition but does not affect growth in the carnivorous plant Pinguicula vulgaris. New Phytol 144: 275-282.

6. Beggs CJ, Wellmann E (1985) Analysis of light-controlled anthocyanin formation in coleoptiles of Zea mays L. The role of UV-B, blue, red and far-red light. Photochem Photobio 41: 481-486.
7. Foot JP, Caporn SJM, Lee JA, Ashenden TW (1996) The effect of longterm ozone fumigation on the growth, physiology, and frost sensitivity of Calluna vulgaris. New Phytol 133: 503-511.

8. Krol M, Gray GR, Hurry VM, Oquist G, Malek L, et al. (1995) Low-temperature stress and photoperiod affect an increased tolerance to photoinhibition in Pinus banksiana seedlings. Can J Bot 73: 1119-1127.

9. McClure JW (1975) Physiology and Functions of Flavonoids. In: Harborne JB, Mabry TJ, Mabry H (eds.). The Flavonoids. Springer, Boston, MA, USA. Pg no: 970-1055.

10. Wang H, Cao G, Prior RL (1997) Oxygen radical absorbing capacity of anthocyanins. J Agric Food Chem 45: 304-309.

11. Stintzing FC, Stintzing AS, Carle R, Frei B, Wrolstad RE (2002) Color and antioxidant properties of cyanidin-based anthocyanin pigments. J Agric Food Chem 50: 6172-6181.

12. Gould KS, McKelvie J, Markham KR (2002) Do anthocyanins function as antioxidants in leaves? Imaging of $\mathrm{H}_{2} \mathrm{O}_{2}$ in red and green leaves after mechanical injury. Plant Cell and Environ 25: 1261-1269.

13. Gould KS, Neill SO, Vogelmann TC (2002) A unified explanation for anthocyanins in leaves? Adv Bot Res 37: 167-192.

14. Steyn WJ, Wand SJE, Holcroft DM, Jacobs G (2002) Anthocyanins in vegetative tissues: a proposed unified function in photoprotection. New Phytol 155: 349-361.

15. Manetas Y (2006) Why some leaves are anthocyanic and why most anthocyanic leaves are red? Flora 201: 163-177. 
Citation: van den Berg AK, Perkins TD (2017) Do Anthocyanins Function as Photoprotective Light Screens in Senescing Sugar Maple Leaves? J Plant Sci Curr Res 1: 002

16. Demmig-Adams B, Adams WW (1992) Photoprotection and other responses of plants to high light stress. Annu Rev Plant Physiol Plant Mol Biol 43: 599-626.

17. Feild TS, Lee DW, Holbrook NM (2001) Why leaves turn red in autumn. The role of anthocyanins in senescing leaves of red-osier dogwood. Plant Physiol 127: 566-574.

18. Manetas Y, Drinia A, Petropoulou Y (2002) High contents of anthocyanins in young leaves are correlated with low pools of xanthophyll cycle components and low risk of photoinhibition. Photosynthetica 40: 349-354.

19. Pietrini F, Iannelli MA, Massacci A (2002) Anthocyanin accumulation in the illuminated surface of maize leaves enhances protection from photo-inhibitory risks at low temperature, without further limitation to photosynthesis. Plant Cell Environment 25: 1251-1259.

20. Hoch WA, Singsaas EL, McCown BH (2003) Resorption protection. Anthocyanins facilitate nutrient recovery in autumn by shielding leaves from potentially damaging light levels. Plant Physiol 133: 1296-1305.

21. Manetas Y, Petropoulou Y, Psaras GK, Drinia A (2003) Exposed red (anthocyanic) leaves of Quercus coccifera display shade characteristics. Functional plant biology 30: 265-270.

22. Hughes NM, Neufeld HS, Burkey KO (2005) Functional role of anthocyanins in high-light winter leaves of the evergreen herb Galax urceolata. New Phytol 168: 575-587.

23. Landi M, Guidi L, Pardossi A, Tattini M, Gould KS (2014) Photoprotection by foliar anthocyanins mitigates effects of boron toxicity in sweet basil (Ocimumbasilicum). Planta 240: 941-953.

24. Burger J, Edwards GE (1996) Photosynthetic efficiency and photodamage by UV and visible radiation, in red versus green leaf Coleus varieties. Plant Cell Physiol 37: 395-399.

25. Hormaetxe K, Becerril JM, Fleck I, Pintó M, García-Plazaola JI (2005) Functional role of red (retro)-carotenoids as passive light filters in the leaves of Buxus sempervirens L.: increased protection of photosynthetic tissues?. J Exp Bot 56: 2629-2636.

26. Karageorgou P, Manetas Y (2006) The importance of being red when young: anthocyanins and the protection of young leaves of Quercus coccifera from insect herbivory and excess light. Tree Physiol 26: 613-621.

27. Kyparissis A, Grammatikopoulos G, Manetas Y (2007) Leaf morphological and physiological adjustments to the spectrally selective shade imposed by anthocyanins in Prunus cerasifera. Tree Physiol 27: 849-857.

28. Kytridis V, Karageorgou P, Levizou E, Manetas Y (2008) Intra-species variation in transient accumulation of leaf anthocyanins in Cistus creticus during winter: Evidence that anthocyanins may compensate for an inherent photosynthetic and photoprotective inferiority of the red-leaf phenotype. J Plant Phys 165: 952-959.
29. Logan BA, Stafstrom WC, Walsh MJL, Reblin JS, Gould KS (2015) Examining the photoprotection hypothesis for adaxial foliar anthocyanin accumulation by revisiting comparisons of green- and red-leafed varieties of coleus (Solenostemon scutellarioides). Photosynth Res 124: 267-274.

30. Esteban R, Fernández-Marin B, Becerril JM, García-Plazaola JI (2008) Photoprotective implications of leaf variegation in E. dens-canis L. and P. officinalis L. J Plant Physiol 165: 1255-1263.

31. Niyogi KK (1999) Photoprotection revisited: genetic and molecular approaches. Annu Rev Plant Physiol Plant Mol Biol 50: 333-359.

32. Matile P, Hortensteiner S, Thomas H (1999) Chlorophyll degradation. Annu Rev Plant Physiol Plant Mol Biol 50: 67-95.

33. Hoch WA, Zeldin EL, McCown BH (2001) Physiological significance of anthocyanins during autumnal leaf senescence. Tree Physiol 21: 1-8.

34. Duan B, Paquette A, Juneau P, Brisson J, Fontaine B, Berninger F (2014) Nitrogen resorption in Acer platanoides and Acer saccharum: influence of light exposure and leaf pigmentation. Acta Physiol 36: 3039-3050.

35. Manetas Y, Buschmann C (2011) The interplay of anthocyanin biosynthesis and chlorophyll catabolism in senescing leaves and the question of photosystem II photoprotection. Photosynthetica 49: 515-522.

36. Lee DW, O’Keefe J, Holbrook NM, Field TS (2003) Pigment dynamics and autumn leaf senescence in a New England deciduous forest, eastern USA. Ecological Research 18: 677-694.

37. Gould KS, Markham KR, Smith RH, Goris JJ (2000) Functional role of anthocyanins in the leaves of Quintinia serrata A. Cunn. J Exp Bot 51: 1107-1115.

38. Lichtenthaler HK, Wellburn AR (1983) Determinations of total carotenoids and chlorophylls $a$ and $b$ of leaf extracts in different solvents. Biochemical Society Transactions 603: 591-592.

39. Murray JR, Hackett WP (1991) Dihydroflavonol reductase activity in relation to differential anthocyanin accumulation in juvenile and mature phase Hedera helix L. Plant Physiol 97: 343-351.

40. Krause GH, Weis E (1991) Chlorophyll fluorescence and photosynthesis: the basics. Annu Rev Plant Physiol Plant Mol Biol 42: 313-349.

41. Maxwell K, Johnson GN (2000) Chlorophyll fluorescence - a practical guide. Journal of Experimental Botany 51: 659-668.

42. van den Berg AK, Vogelmann TC, Perkins TD (2009) Anthocyanin influence on light absorption within juvenile and senescing sugar maple leaves - do anthocyanins function as photoprotective visible light screens? Functional Plant Biology 36: 793-800. 